\title{
Review Article \\ Maternal and Pediatric Health Outcomes in relation to Gestational Vitamin D Sufficiency
}

\author{
Stephen J. Genuis \\ Faculty of Medicine, University of Calgary and University of Alberta, 2935-66 Street, Edmonton, AB, Canada T6K 4C1 \\ Correspondence should be addressed to Stephen J. Genuis; sgenuis@ualberta.ca
}

Received 29 September 2015; Revised 27 October 2015; Accepted 19 November 2015

Academic Editor: W. T. Creasman

Copyright ( 2015 Stephen J. Genuis. This is an open access article distributed under the Creative Commons Attribution License, which permits unrestricted use, distribution, and reproduction in any medium, provided the original work is properly cited.

\begin{abstract}
Juxtaposed with monumental improvement in maternal-fetal outcomes over the last century, there has been the recent emergence of rising rates of gestational complications including preterm birth, operative delivery, and gestational diabetes. At the same time, there has been a burgeoning problem with widespread vitamin D deficiency among populations of many developed nations. This paper provides a brief review of potential health outcomes recently linked to gestational vitamin D deficiency, including preterm birth, cesarean delivery, and gestational diabetes. Although immediate costs for obstetric complications related to gestational vitamin $\mathrm{D}$ insufficiency may be modest, the short- and long-term costs for pediatric healthcare resulting from such gestational complications may be enormous and present an enduring burden on healthcare systems. With increasing evidence pointing to fetal origins of some later life disease, securing vitamin D sufficiency in pregnancy appears to be a simple, safe, and cost-effective measure that can be incorporated into routine preconception and prenatal care in the offices of primary care clinicians. Education on gestational nutritional requirements should be a fundamental part of medical education and residency training, instruction that has been sorely lacking to date.
\end{abstract}

\section{Introduction and Background}

In the early and mid-1800s, the maternal mortality rate in some European obstetrical clinics approached 1 in 5 women as a result of puerperal fever [1]. With the epic discovery of the origins of this "childbed fever" by Ignaz Philipp Semmelweis in the mid-19th century and the eventual knowledge translation of his simple hand washing technique into the clinical domain, rates of postpartum mortality eventually decreased [1]. Over the subsequent century, there continued to be monumental advances in many areas of Maternal-Fetal Medicine. Along with a profound decline in maternal mortality from 7.2 deaths per 1000 births in the early 1900 s to 0.08 by the end of $2000[2,3]$, there was a concomitant decline in infant mortality from 96 to less than 7 deaths per 1000 live births [2,3]. With ongoing research and study over the last decades, remarkable advances have continued to be made in the assessment and management of a variety of gestational and perinatal challenges. Despite much success, however, there are new and emerging concerns in the early 21st century within the field of Maternal-Fetal Medicine.
Along with an astonishing rise in the rate of cesarean delivery with attendant complications to the human microbiome $[4,5]$, we have witnessed a concerning escalation in preterm birth [6], a complication associated with higher rates of long-term physical and mental health problems in the offspring [6-8]. The Institute of Medicine (IOM) estimated the annual costs for the burden of morbidity, disability, and mortality associated with preterm birth in the United States to be at least $\$ 26.2$ billion [9]. Furthermore, the costs associated with neonatal intensive care, healthcare now required by an increasing percentage of the newborn population [10], are staggering [11]. It is also evident that maternal complications do not necessarily stop with giving birth. Rates of serious obstetrical complications such as postpartum depression, for example, extract enormous personal cost and remain a serious and widespread problem [12].

In addition, there is increasing discussion in the literature about fetal origins of pediatric and adult disease $[13,14]$, resulting from potentially modifiable gestational determinants such as disordered maternal nutrition [15] and toxic exposures [16-18]. As this is a new area of study, 
however, the extent of sequelae associated with modifiable gestational determinants is yet unrecognized; it is thus not possible to assign precise costs associated with long-term outcomes. It is important, however, to explore and implement clinical approaches during the preconception and gestational period which address determinants of suboptimal outcomes in order to maximize the enduring health of mothers and their offspring.

\section{Modifiable Gestational Determinants and Illness}

With recent attention to epigenetic research, it is becoming apparent that virtually all disease, including affliction in the gestational period, is the result of the interaction between our genes and the environment [19]. In fact, rather than genetic predestination [20], recent evidence confirms that modifiable environmental factors appear to be responsible for 70-90 percent of clinical illness [21]. Yet within the environmental domain, there appear to be only two determinants which make up the environment sphere. (i) Are we getting what we need? (ii) Are we being exposed to things that are toxic? [19]. Accordingly, it appears that the bulk of human disease, including problems in pregnancy, is related to deficiency and toxicity [19].

Evidence in the obstetric literature appears to support this contention and provides opportunity to make advances with regard to maternal and fetal well-being. In fact, medical intervention and maternal education delivered prior to conception (preconception care) to secure nutritional adequacy and preclude toxic exposures are being extolled as the next frontier of maternal and child healthcare [31]. The March of Dimes, a nonprofit organization dedicated to the health of mothers and babies, suggests that "the [physician] must take advantage of every health encounter to provide preconception care and risk reduction before and between conceptions - the time when it really can make a difference" [32]. With the evident link between fetal determinants and later onset disease, measures to secure an optimal gestational environment can have a profound impact on maternal and pediatric health with enormous personal, social, and financial savings.

There is considerable attention in the literature to the direct link between assorted toxicants in pregnancy and adverse maternal and fetal outcomes [16]. Most recently, FIGO (The International Federation of Obstetrics and Gynecology) released a special communication highlighting the urgent need to address the issue of widespread toxicant exposure and bioaccumulation in reproductive aged women [18]. In addition, it is becoming increasingly apparent that various nutritional deficiencies are widespread and may have an enormous impact on subsequent maternal and fetal health. Increasing evidence appears to confirm that at no point throughout the life cycle is it more important to secure adequate nutrient intake than in pregnancy [26]. This fact, for example, accounts for the emphasis on folate sufficiency in early gestation [33] as well as the increased study into the outcomes related to gestational deficiency of required omega3 fatty acids [34] and magnesium [35].
With the emerging evidence that vitamin $\mathrm{D}$ acts epigenetically in the regulation of over 2700 different genes [36], there has been much recent research exploring the widespread prevalence of vitamin $\mathrm{D}$ deficiency through the continuum of life, including the gestational and neonatal period. This paper is designed to review the literature findings about the enduring impact of gestational vitamin $\mathrm{D}$ sufficiency on maternal and pediatric health and well-being.

\section{Methods}

This brief review was prepared by assessing available medical and scientific literature from Medline as well as by reviewing several books, nutritional journals, conference proceedings, government publications, and nutrition related periodicals. Terms searched included gestational vitamin $\mathrm{D}$, pregnancy and vitamin $\mathrm{D}$, fetus and vitamin $\mathrm{D}$, nutrition in pregnancy, as well as pediatric health and vitamin $\mathrm{D}$. Relevant references found in these publications were also searched in order to glean pertinent information. A primary observation, however, was that limited scientific literature is available on the issue of gestational vitamin D insufficiency as it relates to long-term health outcomes.

The format of a traditional integrated narrative review was chosen as such reviews play a pivotal role in scientific research and professional practice in medical issues spanning different medical disciplines, in this case obstetrics, pediatrics, and general medicine. Furthermore, this type of publication approach seemed apposite when endeavoring to answer specific clinical questions in a field with limited primary study [37]. Finally, it was deemed that a traditional integrated review paper might be optimal when exploring a myriad range of health outcomes, both short and long term.

\section{Clinical Relevance of Vitamin D Sufficiency in Reproductive Healthcare}

The widespread clinical importance of determining the correlation between vitamin D levels and reproductive outcomes is evident. The medical literature has achieved general consensus that vitamin $\mathrm{D}$ levels throughout much of the globe, as reflected by population measurements of $25(\mathrm{OH}) \mathrm{D}_{3}$ levels, are generally inadequate [38]. About $2 / 3$ of the population in northern climates are considered deficient with average $25(\mathrm{OH}) \mathrm{D}_{3}$ levels in one study of $67 \mathrm{nmol} / \mathrm{L}$ [39], well below the $120-150 \mathrm{nmol} / \mathrm{L}$ level that has recently been associated with preferred health [24] (Table 1). With such widespread deficiency, it is vital to determine whether or not low gestational levels of vitamin $\mathrm{D}$ are a significant determinant of reproductive and pediatric health outcomes.

The need for clarity on this issue has also been recognized because of disparity about recommended dosing among esteemed medical groups. While the Institute of Medicine (IOM) agrees that 4,000 IU of vitamin daily is allowable and nontoxic, their actual recommended daily intake has been limited to $600 \mathrm{IU}$ daily in general and $400 \mathrm{IU} /$ day during gestation $[40,41]$. These IOM recommendations for required vitamin D intake have been put into serious question [42], however, as a significant statistical error has been identified 
TABLE 1: Optimal adult levels of vitamin D (as reflected by $25(\mathrm{OH}) \mathrm{D}$ levels) from different sources.

\begin{tabular}{lcc}
\hline Source & $\begin{array}{c}\text { Vitamin D level } \\
(\mathrm{nmol} / \mathrm{L})\end{array}$ & $\begin{array}{c}\text { Vitamin D level } \\
(\mathrm{ng} / \mathrm{mL})\end{array}$ \\
\hline $\begin{array}{l}\text { Holick (2010) [22] } \\
\text { Endocrine Society } \\
\text { (2011) [23] }\end{array}$ & $\begin{array}{c}\text { At least }>75 \text {, aim } \\
\text { for 100 }\end{array}$ & $\begin{array}{c}40-60 \\
\text { At least }>30 \text {, aim } \\
\text { for } 40\end{array}$ \\
$\begin{array}{l}\text { Amrein et al. (2014) } \\
{[24]}\end{array}$ & $120-150$ & $48-60$ \\
$\begin{array}{l}\text { Schwalfenberg and } \\
\text { Genuis (2015) [25] }\end{array}$ & $120-150$ & $48-60$
\end{tabular}

No consensus on a specific optimal 25(OH)D level in pregnancy has been achieved.

Emerging agreement that supplemental vitamin $\mathrm{D}_{3}$ at a dosage of $4000 \mathrm{IU} /$ day throughout pregnancy may be safe and effective [26-30].

in the way their recommendations were arrived at [43]. Accordingly, exploration of consensus findings on the clinical benefits of vitamin $\mathrm{D}$ supplementation is in order in all medical disciplines including reproductive healthcare.

\section{Limitations of Vitamin D Research as Related to Gestational Outcomes}

Although maternal-fetal outcomes in the presence of adequate gestational vitamin $\mathrm{D}$ are generally favorable as reported in the medical literature, some reports have been inconsistent and cast doubt on the link between gestational vitamin D sufficiency and health. Specifically, supplementation of vitamin $\mathrm{D}$ in pregnancy in some studies appears to suggest marked benefit while research in other publications does not appear to confer significant improvement in maternal-fetal outcomes [44]. For example, a systematic review and meta-analysis by Pérez-López et al. found that gestational vitamin D supplementation was associated with increased birth weight and birth length but, unlike some other research, was not associated with other beneficial maternal and neonatal outcomes such as reductions in preeclampsia, gestational diabetes, small for gestational age infants, preterm birth, or rates of cesarean delivery [44]. The apparent disparity between findings in various studies has caused some to reflexively conclude that vitamin D status in pregnancy is irrelevant to maternal-fetal outcomes.

Studies on reproductive outcomes related to vitamin D supplementation, however, are inherently plagued by a number of common confounders which cloud the picture. It is important to realize that vitamin D status is very different from whether or not someone is consuming vitamin $\mathrm{D}$ supplementation. Many factors may affect the resultant status of vitamin $\mathrm{D}$ in the body (as reflected by measurement of $25(\mathrm{OH}) \mathrm{D}$ levels) after ingested supplementation. Dosing of supplements, body weight, levels of various toxicants, and individual metabolism can all be factors in consequent vitamin $\mathrm{D}$ indices after supplementation. Many of the recent publications challenging the efficacy of gestational vitamin D sufficiency have been meta-analyses which attempt to synthesize diverse data from numerous observational and supplementation studies which do not necessarily incorporate individual differences in these central determinants.

Specific concerns about several vitamin D meta-analyses can account for the varying outcomes reported from this type of research. (i) There is wide heterogeneity of studied populations with variations in vitamin $\mathrm{D}$ supplement dosing, geophysical location, social and dietary conditions, and other factors in studied groups [45]. Supplementation at varying doses (e.g., $400 \mathrm{IU} /$ day versus $4000 \mathrm{IU} /$ day), for example, may achieve remarkably different levels of serum 25(OH)D and thus different outcomes. (ii) Commencement of supplementation at differing times during the gestation may miss critical periods when vitamin $\mathrm{D}$ may play a pivotal role. (iii) Different types of vitamin $\mathrm{D}$ (vitamin $\mathrm{D}_{2}$ versus vitamin $\mathrm{D}_{3}$ ) have different physiological impact. And (iv) various methodological concerns are evident [46], such as the lack of standardized assays.

In addition, it is well recognized in healthcare that regardless of how compelling the evidence on a specific scientific or medical issue, introduction of doubt can be a potent impediment to the implementation of effective public health and clinical measures [47, 48]. Accordingly, a critical appraisal of such meta-analyses is in order to achieve an accurate perspective on the efficacy of gestational vitamin $\mathrm{D}$ supplementation.

\section{Gestational Vitamin D Status and Obstetrical Outcomes}

The list of adverse gestational outcomes in pregnancy associated with vitamin D insufficiency continues to mount. Early in pregnancy, for example, an increased risk of first trimester miscarriage has been linked to inadequate maternal vitamin D levels [49]. Interestingly, one study demonstrated that nearly half the women assessed with habitual miscarriage were found to have $25(\mathrm{OH}) \mathrm{D}$ levels below $75 \mathrm{nmol} / \mathrm{L}$ [50]. This research found that lower vitamin D levels were associated with immune dysregulation in a number of ways, including differences in indices involving natural killer cells, various cytokines, and certain regulatory proteins, when compared to those with sufficient vitamin D levels [50]. The authors of this study also noted that women with lower vitamin $\mathrm{D}$ levels had higher degrees of various autoantibodies including antiphospholipid antibody [50], a clinical state that has been associated with fetal death, recurrent early miscarriage, preeclampsia, and placental insufficiency [51].

A number of papers have confirmed an increased risk of developing gestational diabetes in those with inadequate vitamin D levels $[52,53]$. Vitamin D sufficiency in pregnancy appears to be related to improved insulin levels, as well as better glucose regulation as reflected by HbAlc levels [54]. As pregnancies complicated by gestational diabetes present risks for assorted adverse sequelae, efforts to avoid dysregulated sugar control in pregnancy are worthwhile. Obesity presents a confounding influence in this discussion, however, as a greater BMI is associated with lower vitamin D levels as well as greater insulin resistance and risk for gestational diabetes. Numerous studies have also correlated low levels of vitamin D with the development of preeclampsia $[52,53,55,56]$, perhaps 
through immune mechanisms involving antiphospholipid antibody [51], and/or inflammatory mechanisms involving cytokines [56].

Of particular significance is the reality that preterm birth before 37 weeks of gestation remains the leading cause of neonatal morbidity and mortality [57]. Escalating evidence in the literature confirms a protective association between maternal vitamin D sufficiency and the incidence of preterm birth [58-60]. A recent study found that the rate of occurrence of preterm birth appeared to be inversely parallel to the maternal serum 25-hydroxyvitamin D levels [58]. The authors report that the incidence of preterm birth at less than 37 weeks of gestation was (i) $11.3 \%$, (ii) $8.6 \%$, and (iii) $7.3 \%$ among mothers with respective serum 25 -hydroxyvitamin D levels of (i) less than 50, (ii) between 50 and 74.9, and (iii) $75 \mathrm{nmol} / \mathrm{L}$ or greater. Another study found that infants born before 32 weeks of gestation were 2.4 times more likely to have vitamin D levels below $50 \mathrm{nmol} / \mathrm{L}$ when compared with those born after 32 weeks of gestation [61].

Other gestational issues also appear to be influenced by maternal vitamin D levels. Vitamin D insufficiency, for example, has also been correlated with maternal periodontal disease [62], a higher likelihood of small for gestational age infants [63, 64], and an increased risk of bacterial vaginosis [65].

As well as individual studies, systematic reviews exploring association between vitamin D sufficiency and health outcomes have also been illuminating. A systematic review and meta-analysis of 24 studies suggested that low maternal vitamin $\mathrm{D}$ levels in pregnancy may be associated with an increased risk of small for gestational age infants, as well as being linked to preeclampsia, gestational diabetes, and preterm birth [66]. Another systematic review and metaanalysis published in the British Medical Journal also linked vitamin D insufficiency with an increased risk of gestational diabetes, preeclampsia, and small for gestational age infants [65].

Vitamin D status also appears to influence modes of delivery. Vitamin D deficiency has been linked to increased odds of primary cesarean delivery [67] as well as a higher likelihood of emergency cesarean section [68]. In one study, women with vitamin D levels below $37.5 \mathrm{nmol} / \mathrm{L}$ were almost four times as likely to require a primary cesarean delivery as women with higher levels [67]. Through the evolving work on the Human Microbiome Project, it has recently been found that the infant's journey through the birth canal is instrumental in shaping a healthy microbiome, a feature which appears to be a determinant of subsequent health and which may be compromised by cesarean delivery [69]. Accordingly, efforts to diminish the high rates of Cesarean delivery are warranted.

Gestational vitamin D status also appears to influence outcomes beyond the pregnancy and delivery. A very challenging problem for many new mothers is postpartum depression. There is escalating evidence in general that low vitamin $\mathrm{D}$ levels are correlated with higher risk for a variety of mental health problems including depressive illness [70], as vitamin $\mathrm{D}$ is known to play an important role in activating genes that release neurotransmitters such as dopamine and serotonin [70,71]. Intervention to normalize levels of vitamin $\mathrm{D}$ appears to be successful in restoring mental health [72]. In particular, in relation to maternal health, a recent study published in the British Journal of Obstetrics and Gynecology reported that serum 25[OH]D levels in women with no postpartum depression were significantly higher than those in women suffering with postpartum depression [73].

\section{Gestational Vitamin D Status and Later Life Outcomes}

Although research into fetal origins of disease in later life remains in its infancy, there is increasing suspicion that gestational nutritional sufficiency may be a determinant of health in later life. For example, preliminary evidence suggests that insufficient levels of prenatal vitamin D may be a factor in the development of autism [74] and lower respiratory infections [75]. A Spanish study to this end found that mothers who had gestational vitamin $\mathrm{D}$ levels above $75 \mathrm{nmol} / \mathrm{L}$ had offspring with a one-third lower rate of acute respiratory tract infections during the first year of life [76].

A recent body of work has begun to suggest that lower gestational vitamin $\mathrm{D}$ levels may also be associated with higher rates of pediatric atopic disease [77], food sensitivities [78], atopic dermatitis [79], eczema [80], asthma [81], impaired lung function [82], allergic disease [83], and other conditions frequently characterized by a hypersensitive immune state. It appears that fetal vitamin D levels may play a modulating role in immune functions involved in atopic disorders. As hypersensitivity outcomes may also be seen in those children born to mothers contaminated with assorted xenobiotics in pregnancy [84-89], however, it is not known whether the immune dysregulation and hypersensitivity may be the consequence of a primary gestational insufficiency of vitamin $\mathrm{D}$, or whether various chemical toxicants might play a role by impairing vitamin $\mathrm{D}$ uptake, renal synthesis, and assimilation $[25,90]$ while at the same time inducing immune compromise and hypersensitivity through other mechanisms [91].

Maternal vitamin D status during gestation also appears to have influence on many other health indices in the future of the offspring. For example, gestational vitamin D status directly correlates with subsequent whole-body and lumbar spine bone mineral content in progeny at 9 years of age [92]. Furthermore, an interesting cohort study correlating maternal vitamin D deficiency at 18 weeks of pregnancy and health outcomes of progeny found that gestational vitamin $D$ deficiency was associated with impaired lung development in 6-year-old offspring, neurocognitive difficulties at age 10, increased risk of eating disorders in adolescence, and lower peak bone mass at 20 years [93]. The authors state that "vitamin D may have an important, multifaceted role in the development of fetal lungs, brain, and bone" [93]. Finally, gestational vitamin $\mathrm{D}$ levels may impact adult health as there is early evidence that vitamin D sufficiency in pregnancy may have a protective role in the development of adult onset multiple sclerosis [94]. 


\section{Economic Burden of Gestational Vitamin D Deficiency}

The economic impact of vitamin D deficiency as it relates to maternal-fetal health is difficult to objectively quantify as insufficient evidence has accumulated thus far on the totality of short- and long-term sequelae of vitamin D insufficiency. Furthermore, current appraisals tend to underestimate the extent of the required resource utilization for specific conditions associated with vitamin D insufficiency. For example, cost estimates for the immediate care involved with the increase in cesarean delivery rates can be calculated, but these do not at all take into account unexpected surgical complications [95] that may arise in the future or the enormous potential cost impact from enduring microbiome changes resulting from operative delivery $[69,96]$. The reality is that adverse gestational complications do not end with the pregnancy and can result in morbidity and resource utilization extending throughout the life of the offspring.

This is also demonstrated by the challenge of preterm birth, as premature birth results in significant morbidity, mortality, healthcare utilization, and associated costs starting in infancy and extending for years to come [97]. This can be quite a burden on national healthcare systems. In Canada, for example, the estimated additional 10-year cost to care for the children born prematurely each year is hundreds of millions of dollars [98]. Furthermore, many health problems sustained by children born prematurely continue far beyond their tenth birthday with a consequent and sometimes ongoing economic burden placed on health, education, and social service resources. With regard to economic challenges associated with vitamin D insufficiency, suffice it to say that there are considerable costs potentially associated with gestational vitamin D insufficiency [99] as well as corresponding benefits and cost savings resulting from inexpensive supplementation with this essential nutrient [99].

\section{Conclusion}

There is escalating attention in the scientific literature to the association between myriad nutrients and health outcomes $[100,101]$. Training in clinical nutritional biochemistry, nonetheless, still remains woefully inadequate or nonexistent in most medical education programs $[102,103]$. As a result, there are ongoing calls of late for curriculum revision to incorporate practical training in clinical nutrition $[103,104]$. It is apparent that training is required to establish clinical competency in (i) understanding of the role of various nutrients in human health, (ii) how to assess nutritional biochemistry in patients, and (iii) and how to intervene to secure nutrient sufficiency for individuals and population groups

With the mounting evidence of several health sequelae associated with gestational vitamin $\mathrm{D}$ deficiency, the value of preconception education and care by health providers and public health bodies to secure vitamin D sufficiency throughout gestation is evident. As pregnant women [105], particularly those with dark skin [106], are at considerable risk for experiencing vitamin D insufficiency [39], it is important to have a high index of suspicion and to effectively preclude, assess for, and manage vitamin $\mathrm{D}$ inadequacy, as would be done with other biochemical irregularities.

Although (to the author's knowledge) there are no specific target levels for $25(\mathrm{OH}) \mathrm{D}$ during the various stages of pregnancy that correlate with optimal results in relation to maternal and pediatric health outcomes, some authors have made recommendations for supplemental levels that appear to be safe and effective. These recommendations range from $600 \mathrm{IU} /$ day from the Institute of Medicine [41] to $2000 \mathrm{IU} /$ day from the Canadian Pediatric Society [107], to 4000 IU/daily from various researchers who have concluded that the latter dose is both efficacious and safe [26-30]. One researcher has suggested that the dietary requirement during pregnancy and lactation may actually be as high as 6000 IU/day [108], but most researchers have concluded, with our current knowledge, that a supplemental vitamin D intake of $4000 \mathrm{IU} /$ day is optimal [30]. As discussed, individual vitamin D indices can be influenced by various determinants despite specific levels of supplementation; it is thus the author's recommendation that a personalized medical approach be taken via individual screening for $25(\mathrm{OH}) \mathrm{D}$ as a routine part of preconception and prenatal care.

With evidence that a major proportion of the adult population [38], particularly in northern climates [39], is potentially deficient in vitamin $\mathrm{D}$, it appears that, at minimum, one out of every few expectant mothers will have inadequate levels of this essential nutrient. With the recognition that vitamin $\mathrm{D}$ plays an essential role in myriad genes that encode for health and well-being in the offspring, it behooves the medical and public health community to endeavor to secure vitamin $\mathrm{D}$ adequacy in the gestational period. The ongoing personal health burden associated with gestational vitamin $\mathrm{D}$ insufficiency throughout many parts of the world has the potential to be ameliorated considerably by straightforward educational and healthcare measures in the preconception and prenatal period to secure vitamin $\mathrm{D}$ sufficiency throughout pregnancy. It is time for maternity health providers to be apprised of the potential for improved and enduring health and well-being associated with inexpensive measures to secure vitamin $\mathrm{D}$ nutritional adequacy during gestation, the most vulnerable time in the life cycle of the developing child.

\section{Conflict of Interests}

There is no conflict of interests.

\section{References}

[1] H. F. Spirer and L. Spirer, "Death and numbers: Semmelweis the statistician," Physicians for Social Responsibility Quarterly, vol. 1, pp. 43-52, 1991.

[2] United States Department of Health Education and Welfare, Infant, Fetal, and Maternal Mortality: United States-1963, United States Department of Health, Washington, DC, USA, 1966, http://www.cdc.gov/nchs/data/series/sr_20/sr20_003acc .pdf.

[3] United States Department of Health and Human Services, Health-United States 2004, Hyattsville, Md, USA, http://www .cdc.gov/nchs/data/hus/hus04.pdf. 
[4] G. Biasucci, M. Rubini, S. Riboni, L. Morelli, E. Bessi, and C. Retetangos, "Mode of delivery affects the bacterial community in the newborn gut," Early Human Development, vol. 86, supplement 1, pp. S13-S15, 2010.

[5] S. Dogra, O. Sakwinska, S. Soh et al., "Dynamics of infant gut microbiota are influenced by delivery mode and gestational duration and are associated with subsequent adiposity," mBio, vol. 6, no. 1, Article ID e02419-14, 2015.

[6] E. R. B. McCabe, G. E. Carrino, R. B. Russell, and J. L. Howse, "Fighting for the next generation: US prematurity in 2030," Pediatrics, vol. 134, no. 6, pp. 1193-1199, 2014.

[7] R. W. Loftin, M. Habli, C. C. Snyder, C. M. Cormier, D. F. Lewis, and E. A. Defranco, "Late preterm birth," Reviews in Obstetrics \& Gynecology, vol. 3, no. 1, pp. 10-19, 2010.

[8] M. C. McCormick, "The contribution of low birth weight to infant mortality and childhood morbidity," The New England Journal of Medicine, vol. 312, no. 2, pp. 82-90, 1985.

[9] R. E. Behrman, A. S. Butler, and Institute of Medicine (US) Committee on Understanding Premature Birth and Assuring Healthy Outcomes, Preterm Birth: Causes, Consequences, and Prevention, National Academies Press, Washington, DC, USA, 2007.

[10] W. Harrison and D. Goodman, "Epidemiologic trends in neonatal intensive care, 2007-2012," JAMA Pediatrics, vol. 169, no. 9, pp. 855-862, 2015.

[11] A. Ramachandrappa and L. Jain, "Health issues of the late preterm infant," Pediatric Clinics of North America, vol. 56, no. 3, pp. 565-577, 2009.

[12] T. Cristescu, S. Behrman, S. V. Jones, L. Chouliaras, and K. P. Ebmeier, "Be vigilant for perinatal mental health problems," Practitioner, vol. 259, no. 1780, pp. 19-23, 2015.

[13] S. Visentin, F. Grumolato, G. B. Nardelli, B. Di Camillo, E. Grisan, and E. Cosmi, "Early origins of adult disease: low birth weight and vascular remodeling," Atherosclerosis, vol. 237, no. 2, pp. 391-399, 2014.

[14] R. H. Lane, "Fetal programming, epigenetics, and adult onset disease," Clinics in Perinatology, vol. 41, no. 4, pp. 815-831, 2014.

[15] M. Weber, J. M. Ayoubi, and O. Picone, "Nutrition of pregnant women: consequences for fetal growth and adult diseases," Archives de Pédiatrie, vol. 22, no. 1, pp. 116-118, 2015.

[16] S. J. Genuis, "The chemical erosion of human health: adverse environmental exposure and in-utero pollution-determinants of congenital disorders and chronic disease," Journal of Perinatal Medicine, vol. 34, no. 3, pp. 185-195, 2006.

[17] D. A. Rossignol, S. J. Genuis, and R. E. Frye, "Environmental toxicants and autism spectrum disorders: a systematic review," Translational Psychiatry, vol. 4, no. 2, article e360, 2014.

[18] G. C. Di Renzo, J. A. Conry, J. Blake et al., "International federation of gynecology and obstetrics opinion on reproductive health impacts of exposure to toxic environmental chemicals," International Journal of Gynecology \& Obstetrics, vol. 131, no. 3, pp. 219-225, 2015.

[19] S. J. Genuis, "What's out there making us sick?" Journal of Environmental and Public Health, vol. 2012, Article ID 605137, 10 pages, 2012.

[20] S. J. Genuis, "Our genes are not our destiny: incorporating molecular medicine into clinical practice," Journal of Evaluation in Clinical Practice, vol. 14, no. 1, pp. 94-102, 2008.

[21] S. M. Rappaport and M. T. Smith, "Epidemiology. Environment and disease risks," Science, vol. 330, no. 6003, pp. 460-461, 2010.
[22] M. F. Holick, "Vitamin D and health: evaluation, biologic functions, and recommended dietary intake for vitamin D," in Vitamin D: Physiology, Molecular Biology, and Clinical Applications, pp. 3-35, Springer, New York, NY, USA, 2010.

[23] M. F. Holick, N. C. Binkley, H. A. Bischoff-Ferrari et al., "Evaluation, treatment, and prevention of vitamin D deficiency: an Endocrine Society clinical practice guideline," The Journal of Clinical Endocrinology \& Metabolism, vol. 96, no. 7, pp. 19111930, 1911.

[24] K. Amrein, S. A. Quraishi, A. A. Litonjua et al., "Evidence for a U-shaped relationship between prehospital vitamin D status and mortality: a cohort study," The Journal of Clinical Endocrinology \& Metabolism, vol. 99, no. 4, pp. 1461-1469, 2014.

[25] G. K. Schwalfenberg and S. J. Genuis, "Vitamin D, essential minerals, and toxic elements: exploring interactions between nutrients and toxicants in clinical medicine," The Scientific World Journal, vol. 2015, Article ID 318595, 8 pages, 2015.

[26] B. W. Hollis, D. Johnson, T. C. Hulsey, M. Ebeling, and C. L. Wagner, "Vitamin D supplementation during pregnancy: double-blind, randomized clinical trial of safety and effectiveness," Journal of Bone and Mineral Research, vol. 26, no. 10, pp. 2341-2357, 2011.

[27] A. Dawodu, H. F. Saadi, G. Bekdache, Y. Javed, M. Altaye, and B. W. Hollis, "Randomized controlled trial (RCT) of vitamin D supplementation in pregnancy in a population with endemic vitamin D deficiency," Journal of Clinical Endocrinology and Metabolism, vol. 98, no. 6, pp. 2337-2346, 2013.

[28] C. L. Wagner, R. B. McNeil, D. D. Johnson et al., "Health characteristics and outcomes of two randomized vitamin $\mathrm{D}$ supplementation trials during pregnancy: a combined analysis," The Journal of Steroid Biochemistry and Molecular Biology, vol. 136, pp. 313-320, 2013.

[29] C. L. Wagner, R. McNeil, S. A. Hamilton et al., "A randomized trial of vitamin D supplementation in 2 community health center networks in South Carolina," American Journal of Obstetrics and Gynecology, vol. 208, no. 2, pp. 137.el-137.el3, 2013.

[30] A. Mithal and S. Kalra, "Vitamin D supplementation in pregnancy," Indian Journal of Endocrinology and Metabolism, vol. 18, no. 5, pp. 593-596, 2014.

[31] H. K. Atrash, K. Johnson, M. Adams, J. F. Cordero, and J. Howse, "Preconception care for improving perinatal outcomes: the time to act," Maternal and Child Health Journal, vol. 10, supplement 1, pp. S3-S11, 2006.

[32] March of Dimes Birth Defects Foundation, "March of dimes updates: is early prenatal care too late?" Contemporary $O B / G Y N$, vol. 12, pp. 54-72, 2002.

[33] G. Barkai, S. Arbuzova, M. Berkenstadt, S. Heifetz, and H. Cuckle, "Frequency of Down's syndrome and neural-tube defects in the same family," The Lancet, vol. 361, no. 9366, pp. 1331-1335, 2003.

[34] K. A. Mulder, D. J. King, S. M. Innis, and H. R. Baradaran, "Omega-3 fatty acid deficiency in infants before birth identified using a randomized trial of maternal DHA supplementation in pregnancy," PLoS ONE, vol. 9, no. 1, Article ID e83764, 2014.

[35] J. Takaya and K. Kaneko, "Small for gestational age and magnesium in cord blood platelets: intrauterine magnesium deficiency may induce metabolic syndrome in later life," Journal of Pregnancy, vol. 2011, Article ID 270474, 5 pages, 2011.

[36] S. V. Ramagopalan, A. Heger, A. J. Berlanga et al., "A ChIPseq defined genome-wide map of vitamin $\mathrm{D}$ receptor binding: associations with disease and evolution," Genome Research, vol. 20, no. 10, pp. 1352-1360, 2010. 
[37] M. P. Dijkers, "The value of traditional reviews in the era of systematic reviewing," American Journal of Physical Medicine \& Rehabilitation, vol. 88, no. 5, pp. 423-430, 1963.

[38] M. F. Holick and T. C. Chen, "Vitamin D deficiency: a worldwide problem with health consequences," The American Journal of Clinical Nutrition, vol. 87, no. 4, pp. 1080S-1086S, 2008.

[39] S. J. Genuis, G. K. Schwalfenberg, M. N. Hiltz, and S. A. Vaselenak, "Vitamin D status of clinical practice populations at higher latitudes: analysis and applications," International Journal of Environmental Research and Public Health, vol. 6, no. 1, pp. 151-173, 2009.

[40] A. C. Ross, J. E. Manson, S. A. Abrams et al., “The 2011 report on dietary reference intakes for calcium and vitamin $\mathrm{D}$ from the Institute of Medicine: what clinicians need to know," The Journal of Clinical Endocrinology \& Metabolism, vol. 96, no. 1, pp. 53-58, 2011.

[41] Institute of Medicine, Dietary Reference Intakes for Calcium and Vitamin D, National Academies Press, Washington, DC, USA, 2010.

[42] G. K. Schwalfenberg and S. J. Whiting, "A Canadian response to the 2010 Institute of Medicine vitamin D and calcium guidelines," Public Health Nutrition, vol. 14, no. 4, pp. 746-748, 2011.

[43] P. J. Veugelers and J. P. Ekwaru, "A statistical error in the estimation of the recommended dietary allowance for vitamin D," Nutrients, vol. 6, no. 10, pp. 4472-4475, 2014.

[44] F. R. Pérez-López, V. Pasupuleti, E. Mezones-Holguin et al., "Effect of vitamin D supplementation during pregnancy on maternal and neonatal outcomes: a systematic review and metaanalysis of randomized controlled trials," Fertility and Sterility, vol. 103, no. 5, pp. 1278.e4-1288.e4, 2015.

[45] S. N. Karras, P. Anagnostis, S. A. Paschou, E. Kandaraki, and D. G. Goulis, "Vitamin D status during pregnancy: time for a more unified approach beyond borders?" European Journal of Clinical Nutrition, vol. 69, no. 8, pp. 874-877, 2015.

[46] S. N. Karras, P. Anagnostis, A. Petroczi, C. Annweiler, D. P. Naughton, and D. P. Goulis, "Maternal vitamin D status in pregnancy: a critical appraisal of current analytical data on maternal and neonatal outcomes," Hormones, vol. 14, no. 2, pp. 224231, 2015.

[47] D. Michaels, Doubt Is Their Product: How Industry's Assault on Science Threatens Your Health, Oxford University Press, New York, NY, USA, 2008.

[48] S. J. Genuis and C. T. Lipp, "Electromagnetic hypersensitivity: fact or fiction?" The Science of the Total Environment, vol. 414, pp. 103-112, 2012.

[49] L. B. Andersen, J. S. Jørgensen, T. K. Jensen et al., "Vitamin D insufficiency is associated with increased risk of first-trimester miscarriage in the Odense Child Cohort," The American Journal of Clinical Nutrition, vol. 102, no. 3, pp. 633-638, 2015.

[50] K. Ota, S. Dambaeva, A.-R. Han, K. Beaman, A. Gilman-Sachs, and J. Kwak-Kim, "Vitamin D deficiency may be a risk factor for recurrent pregnancy losses by increasing cellular immunity and autoimmunity," Human Reproduction, vol. 29, no. 2, pp. 208219, 2014.

[51] R. A. Levy, F. C. Dos Santos, G. R. de Jesus, and N. R. de Jesus, "Antiphospholipid antibodies and antiphospholipid syndrome during pregnancy: diagnostic concepts," Frontiers in Immunology, vol. 6, article 205, 2015.

[52] D. K. Dror, "Vitamin D status during pregnancy: maternal, fetal, and postnatal outcomes," Current Opinion in Obstetrics \& Gynecology, vol. 23, no. 6, pp. 422-426, 2011.
[53] P. M. Brannon, "Vitamin D and adverse pregnancy outcomes: beyond bone health and growth," Proceedings of the Nutrition Society, vol. 71, no. 2, pp. 205-212, 2012.

[54] A. El Lithy, R. M. Abdella, Y. M. El-Faissal, A. M. Sayed, and R. M. Samie, "The relationship between low maternal serum vitamin D levels and glycemic control in gestational diabetes assessed by HbAlc levels: an observational cross-sectional study," BMC Pregnancy and Childbirth, vol. 14, article 362, 2014.

[55] L. M. Bodnar, J. M. Catov, H. N. Simhan, M. F. Holick, R. W. Powers, and J. M. Roberts, "Maternal vitamin D deficiency increases the risk of preeclampsia," Journal of Clinical Endocrinology and Metabolism, vol. 92, no. 9, pp. 3517-3522, 2007.

[56] D. Barrera, L. Díaz, N. Noyola-Martínez, and A. Halhali, "Vitamin D and inflammatory cytokines in healthy and preeclamptic pregnancies," Nutrients, vol. 7, no. 8, pp. 6465-6490, 2015.

[57] Y. J. Heng, S. Liong, M. Permezel, G. E. Rice, M. K. Di Quinzio, and H. M. Georgiou, "Human cervicovaginal fluid biomarkers to predict term and preterm labor," Frontiers in Physiology, vol. 6, article 151, 2015.

[58] L. M. Bodnar, R. W. Platt, and H. N. Simhan, "Early-pregnancy vitamin D deficiency and risk of preterm birth subtypes," Obstetrics \& Gynecology, vol. 125, no. 2, pp. 439-447, 2015.

[59] T. Zhu, T. J. Liu, X. Ge, J. Kong, L. J. Zhang, and Q. Zhao, "High prevalence of maternal vitamin $\mathrm{D}$ deficiency in preterm births in northeast China, Shenyang," International Journal of Clinical and Experimental Pathology, vol. 8, no. 2, Article ID 25973031, pp. 1459-1465, 2015.

[60] C. L. Wagner, C. Baggerly, S. McDonnell et al., "Post-hoc analysis of vitamin D status and reduced risk of preterm birth in two vitamin D pregnancy cohorts compared with South Carolina March of Dimes 2009-2011 rates," The Journal of Steroid Biochemistry and Molecular Biology, 2015.

[61] H. H. Burris, L. J. Van Marter, T. F. McElrath et al., "Vitamin D status among preterm and full-term infants at birth," Pediatric Research, vol. 75, no. 1, pp. 75-80, 2014.

[62] K. A. Boggess, J. A. Espinola, K. Moss, J. Beck, S. Offenbacher, and C. A. Camargo Jr., "Vitamin D status and periodontal disease among pregnant women," Journal of Periodontology, vol. 82, no. 2, pp. 195-200, 2011.

[63] Y. H. Chen, L. Fu, J. H. Hao et al., "Maternal vitamin D deficiency during pregnancy elevates the risks of small for gestational age and low birth weight infants in Chinese population," The Journal of Clinical Endocrinology \& Metabolism, vol. 100, no. 5, pp. 1912-1919, 2015.

[64] P. Zhu, S.-L. Tong, W.-B. Hu et al., "Cord blood 25-hydroxyvitamin D and fetal growth in the China-Anhui birth cohort study," Scientific Reports, vol. 5, Article ID 14930, 2015.

[65] F. Aghajafari, T. Nagulesapillai, P. E. Ronksley, S. C. Tough, M. O'Beirne, and D. M. Rabi, "Association between maternal serum 25-hydroxyvitamin D level and pregnancy and neonatal outcomes: systematic review and meta-analysis of observational studies," The BMJ, vol. 346, article f1169, 2013.

[66] S. Q. Wei, H. P. Qi, Z. C. Luo, and W. D. Fraser, "Maternal vitamin $\mathrm{D}$ status and adverse pregnancy outcomes: a systematic review and meta-analysis," The Journal of Maternal-Fetal of Neonatal Medicine, vol. 26, no. 9, pp. 889-899, 2013.

[67] A. Merewood, S. D. Mehta, T. C. Chen, H. Bauchner, and M. F. Holick, "Association between vitamin D deficiency and primary cesarean section," The Journal of Clinical Endocrinology \& Metabolism, vol. 94, no. 3, pp. 940-945, 2009.

[68] S. L. Loy, N. Lek, F. Yap et al., "Association of maternal vitamin D status with glucose tolerance and caesarean section in a 
multi-ethnic Asian cohort: the growing up in Singapore towards healthy outcomes study," PLoS ONE, vol. 10, no. 11, Article ID e0142239, 2015.

[69] I. Solt, "The human microbiome and the great obstetrical syndromes: a new frontier in maternal-fetal medicine," Best Practice \& Research Clinical Obstetrics \& Gynaecology, vol. 29, no. 2, pp. 165-175, 2015.

[70] W. J. G. Hoogendijk, P. Lips, M. G. Dik, D. J. H. Deeg, A. T. F. Beekman, and B. W. J. H. Penninx, "Depression is associated with decreased 25-hydroxyvitamin D and increased parathyroid hormone levels in older adults," Archives of General Psychiatry, vol. 65, no. 5, pp. 508-512, 2008.

[71] D. Eyles, J. Brown, A. Mackay-Sim, J. McGrath, and F. Feron, "Vitamin D3 and brain development," Neuroscience, vol. 118, no. 3, pp. 641-653, 2003.

[72] R. Vieth, S. Kimball, A. Hu, and P. G. Walfish, "Randomized comparison of the effects of the vitamin D3 adequate intake versus $100 \mathrm{mcg}$ (4000 IU) per day on biochemical responses and the wellbeing of patients," Nutrition Journal, vol. 3, article 8 , 2004.

[73] C. W. Fu, J. T. Liu, W. J. Tu, J. Q. Yang, and Y. Cao, “Association between serum 25-hydroxyvitamin D levels measured 24 hours after delivery and postpartum depression," BJOG, vol. 122, no. 12, pp. 1688-1694, 2015.

[74] E. Fernell, S. Bejerot, J. Westerlund et al., "Autism spectrum disorder and low vitamin D at birth: a sibling control study," Molecular Autism, vol. 6, article 3, 2015.

[75] M. C. Magnus, L. C. Stene, S. E. Haberg et al., "Prospective study of maternal mid-pregnancy 25-hydroxyvitamin D level and early childhood respiratory disorders," Paediatric and Perinatal Epidemiology, vol. 27, no. 6, pp. 532-541, 2013.

[76] E. Morales, I. Romieu, S. Guerra et al., "Maternal vitamin D status in pregnancy and risk of lower respiratory tract infections, wheezing, and asthma in offspring," Epidemiology, vol. 23, no. 1, pp. 64-71, 2012.

[77] C.-Y. Chiu, S.-Y. Huang, Y.-C. Peng et al., "Maternal vitamin D levels are inversely related to allergic sensitization and atopic diseases in early childhood," Pediatric Allergy and Immunology, vol. 26, no. 4, pp. 337-343, 2015.

[78] C.-Y. Chiu, T.-S. Yao, S.-H. Chen et al., "Low cord blood vitamin D levels are associated with increased milk sensitization in early childhood," Pediatric Allergy and Immunology, vol. 25, no. 8, pp. 767-772, 2014.

[79] N. Baï, P. Dargent-Molina, J. D. Wark, J.-C. Souberbielle, and I. Annesi-Maesano, "Cord serum 25-hydroxyvitamin D and risk of early childhood transient wheezing and atopic dermatitis," Journal of Allergy and Clinical Immunology, vol. 133, no. 1, pp. 147-153, 2014.

[80] D. J. Palmer, T. R. Sullivan, C. M. Skeaff, L. G. Smithers, and M. Makrides, "Higher cord blood 25-hydroxyvitamin D concentrations reduce the risk of early childhood eczema: in children with a family history of allergic disease," World Allergy Organization Journal, vol. 8, no. 1, article 28, 2015.

[81] T. Gazibara, H. T. den Dekker, J. C. de Jongste et al., "Associations of maternal and fetal 25-hydroxyvitamin D levels with childhood lung function and asthma. The Generation R Study," Clinical \& Experimental Allergy, 2015.

[82] G. R. Zosky, P. H. Hart, A. J. O. Whitehouse et al., "Vitamin $\mathrm{D}$ deficiency at 16 to 20 weeks' gestation is associated with impaired lung function and asthma at 6 years of age," Annals of the American Thoracic Society, vol. 11, no. 4, pp. 571-577, 2014.
[83] C. Benetti, P. Comberiati, C. Capristo, A. L. Boner, and D. G. Peroni, "Therapeutic effects of vitamin D in asthma and allergy," Mini-Reviews in Medicinal Chemistry, vol. 15, no. 11, pp. 935943, 2015.

[84] W. Jedrychowski, A. Galas, A. Pac et al., "Prenatal ambient air exposure to polycyclic aromatic hydrocarbons and the occurrence of respiratory symptoms over the first year of life," European Journal of Epidemiology, vol. 20, no. 9, pp. 775-782, 2005.

[85] W. Jedrychowski, F. Perera, U. Maugeri et al., "Intrauterine exposure to lead may enhance sensitization to common inhalant allergens in early childhood: a prospective prebirth cohort study," Environmental Research, vol. 111, no. 1, pp. 119124, 2011.

[86] P. Grandjean, L. K. Poulsen, C. Heilmann, U. Steuerwald, and P. Weihe, "Allergy and sensitization during childhood associated with prenatal and lactational exposure to marine pollutants," Environmental Health Perspectives, vol. 118, no. 10, pp. 1429$1433,2010$.

[87] E. Okada, S. Sasaki, Y. Saijo et al., "Prenatal exposure to perfluorinated chemicals and relationship with allergies and infectious diseases in infants," Environmental Research, vol. 112, pp. 118-125, 2012.

[88] C. Miyashita, S. Sasaki, Y. Saijo et al., "Effects of prenatal exposure to dioxin-like compounds on allergies and infections during infancy," Environmental Research, vol. 111, no. 4, pp. 551558,2011

[89] S. B. Stolevik, U. C. Nygaard, E. Namork et al., "Prenatal exposure to polychlorinated biphenyls and dioxins is associated with increased risk of wheeze and infections in infants," Food and Chemical Toxicology, vol. 49, no. 8, pp. 1843-1848, 2011.

[90] J. Moon, "The role of vitamin D in toxic metal absorption: a review," Journal of the American College of Nutrition, vol. 13, no. 6, pp. 559-564, 1994.

[91] S. J. Genuis, "Sensitivity-related illness: the escalating pandemic of allergy, food intolerance and chemical sensitivity," The Science of the Total Environment, vol. 408, no. 24, pp. 6047-6061, 2010.

[92] M. K. Javaid, S. R. Crozier, N. C. Harvey et al., "Maternal vitamin D status during pregnancy and childhood bone mass at age 9 years: a longitudinal study," The Lancet, vol. 367, no. 9504, pp. 36-43, 2006.

[93] P. H. Hart, R. M. Lucas, J. P. Walsh et al., "Vitamin D in fetal development: findings from a birth cohort study," Pediatrics, vol. 135, no. 1, pp. e167-e173, 2015.

[94] F. Mirzaei, K. B. Michels, K. Munger et al., "Gestational vitamin $\mathrm{D}$ and the risk of multiple sclerosis in offspring," Annals of Neurology, vol. 70, no. 1, pp. 30-40, 2011.

[95] N. Al-Asmari and T. Tulandi, "The relevance of post-cesarean adhesions," Surgical Technology International, vol. 22, pp. 177181, 2012.

[96] J. Sonnenburg and E. Sonnenburg, The Good Gut: Taking Control of Your Weight, Your Mood, and Your Long-Term Health, Bantam Press, London, UK, 2015.

[97] S. Beck, D. Wojdyla, L. Say et al., "The worldwide incidence of preterm birth: a systematic review of maternal mortality and morbidity," Bulletin of the World Health Organization, vol. 88, no. 1, pp. 31-38, 2010.

[98] K. M. Johnston, K. Gooch, E. Korol et al., "The economic burden of prematurity in Canada," BMC Pediatrics, vol. 14, article 93, 2014. 
[99] W. B. Grant, G. K. Schwalfenberg, S. J. Genuis, and S. J. Whiting, "An estimate of the economic burden and premature deaths due to vitamin D deficiency in Canada," Molecular Nutrition \& Food Research, vol. 54, no. 8, pp. 1172-1181, 2010.

[100] S. M. Solon-Biet, S. J. Mitchell, R. de Cabo, D. Raubenheimer, D. G. Le Couteur, and S. J. Simpson, "Macronutrients and caloric intake in health and longevity," Journal of Endocrinology, vol. 226, no. 1, pp. R17-R28, 2015.

[101] S. J. Genuis, "Nutritional transition: a determinant of global health," Journal of Epidemiology and Community Health, vol. 59, no. 8, pp. 615-617, 2005.

[102] J. Crowley, L. Ball, C. Wall, and M. Leveritt, "Nutrition beyond drugs and devices: a review of the approaches to enhance the capacity of nutrition care provision by general practitioners," Australian Journal of Primary Health, vol. 18, no. 2, pp. 90-95, 2012.

[103] M. Castillo, R. Feinstein, J. Tsang, and M. Fisher, "Basic nutrition knowledge of recent medical graduates entering a pediatric residency program," International Journal of Adolescent Medicine and Health, 2015.

[104] C. Lo, "Integrating nutrition as a theme throughout the medical school curriculum," The American Journal of Clinical Nutrition, vol. 72, no. 3, supplement, pp. 882S-889S, 2000.

[105] D. C. Lehotay, P. Smith, J. Krahn, M. Etter, and J. Eichhorst, "Vitamin D levels and relative insufficiency in Saskatchewan," Clinical Biochemistry, vol. 46, no. 15, pp. 1489-1492, 2013.

[106] M. Aucoin, R. Weaver, R. Thomas, and L. Jones, "Vitamin D status of refugees arriving in Canada: findings from the calgary refugee health program," Canadian Family Physician, vol. 59, no. 4, pp. e188-e194, 2013.

[107] Canadian Pediatric Society, "Vitamin D supplementation: recommendations for Canadian mothers and infants," Paediatrics \& Child Health, vol. 12, no. 7, pp. 583-598, 2007.

[108] B. W. Hollis, "Vitamin D requirement during pregnancy and lactation," Journal of Bone and Mineral Research, vol. 22, supplement 2, pp. V39-V44, 2007. 


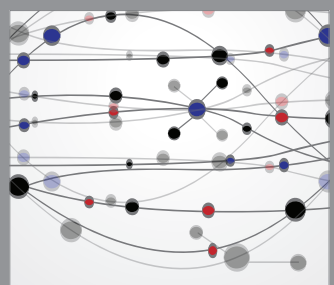

The Scientific World Journal
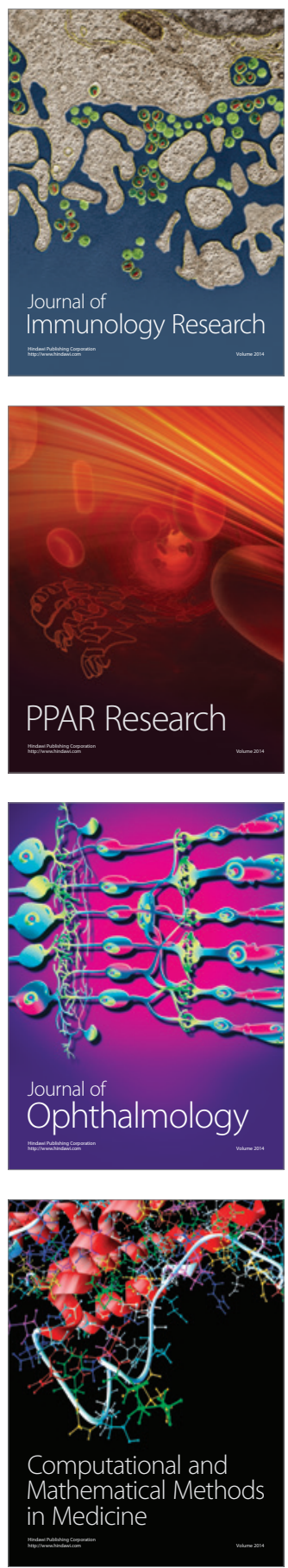

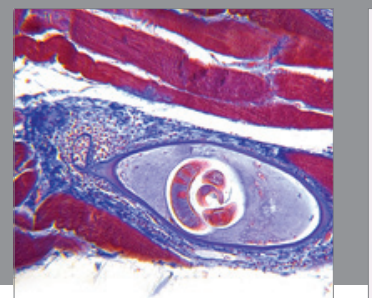

Gastroenterology

Research and Practice
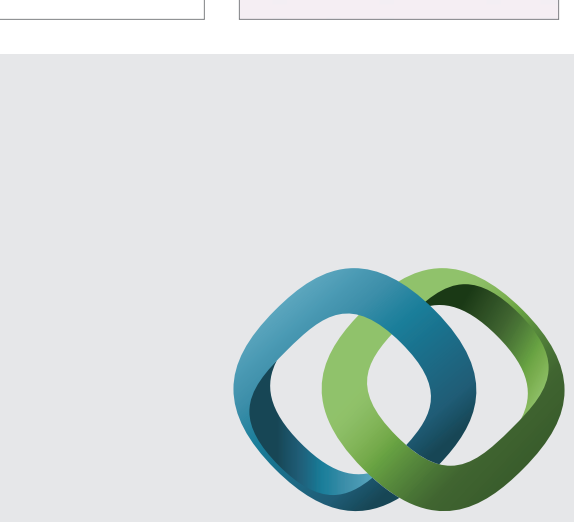

\section{Hindawi}

Submit your manuscripts at

http://www.hindawi.com
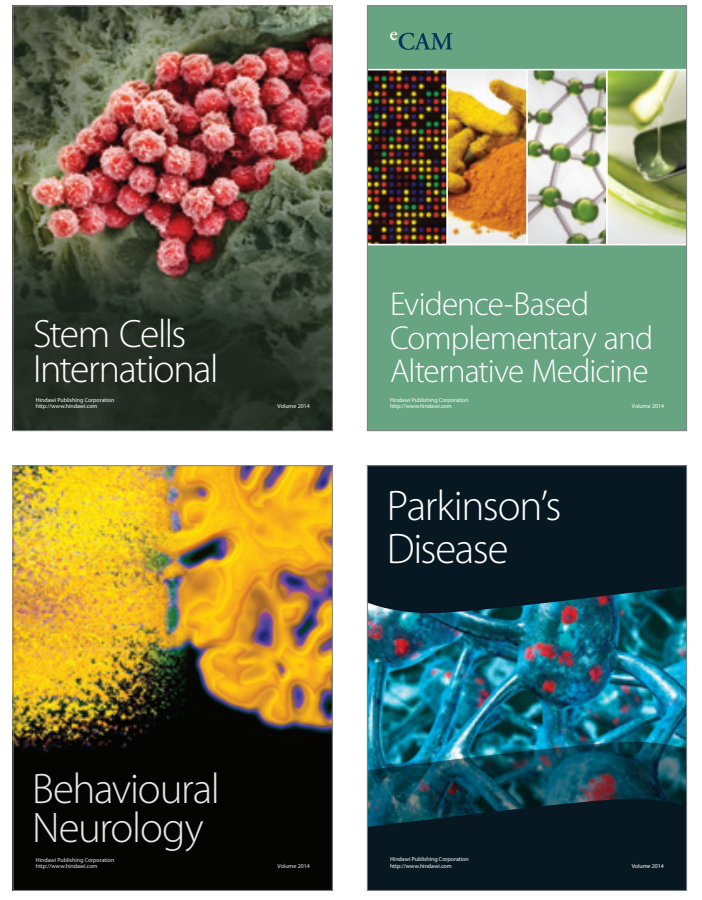
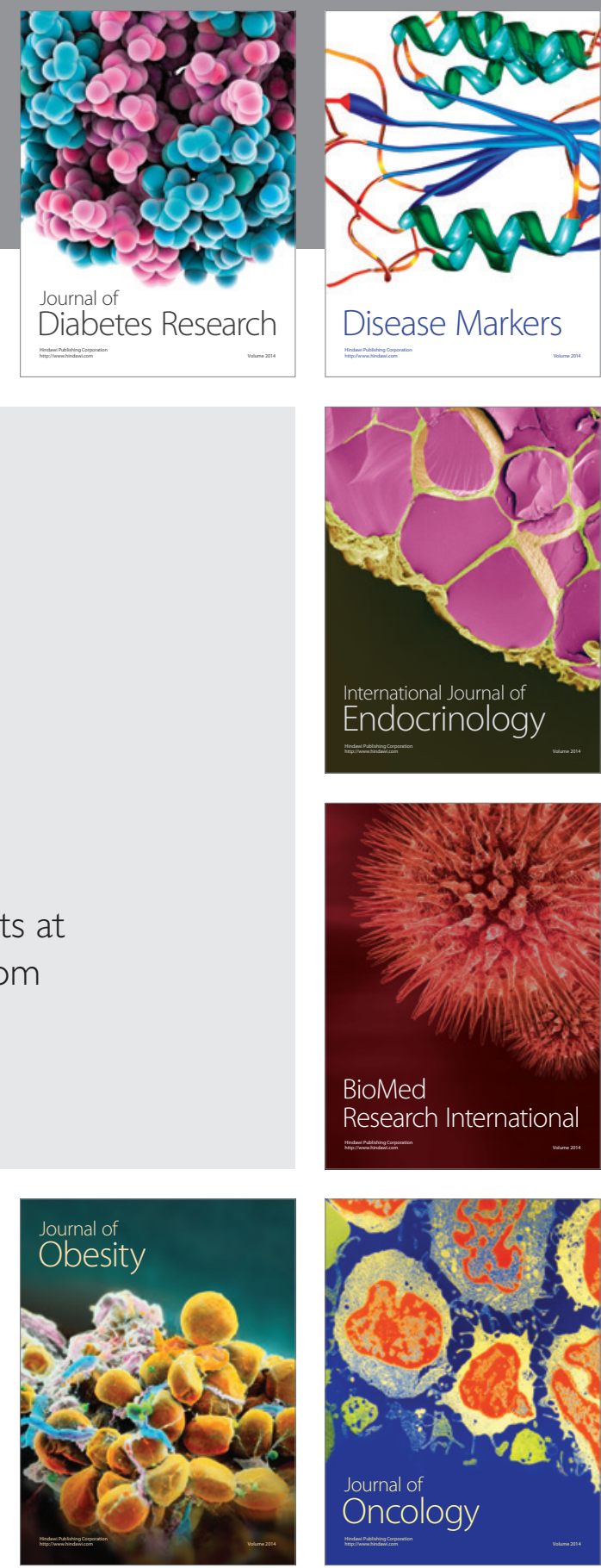

Disease Markers
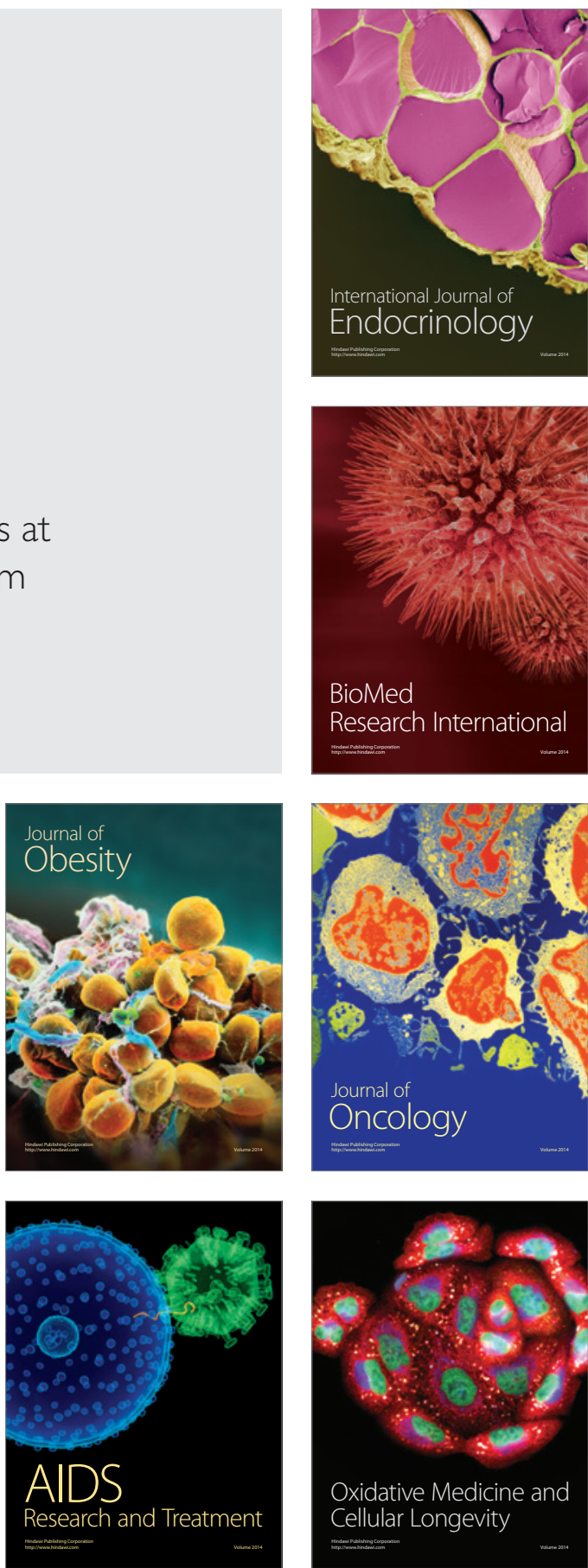